\title{
Development and Evaluation of a Loop-Mediated Isothermal Amplification Assay Combined with Enrichment Culture for Rapid Detection of Very Low Numbers of Vibrio parahaemolyticus in Seafood Samples
}

\author{
Huiling Di, ${ }^{a}$ Lei Ye, ${ }^{a}$ Sucharit Basu Neogi,,${ }^{a \dagger}$ Hecheng Meng, ${ }^{b}$ He Yan, ${ }^{a}$ Shinji Yamasaki, ${ }^{* a, b}$ and \\ Lei $\mathrm{Sh}^{a}$ \\ ${ }^{a}$ College of Light Industry and Food Sciences, South China University of Technology; Guangzhou 510640, P.R. \\ China: and ${ }^{b}$ Graduate School of Life and Environmental Sciences, Osaka Prefecture University; Osaka 598-8531, \\ Japan. \\ Received August 11, 2014; accepted October 10, 2014
}

\begin{abstract}
The aim of this study was to develop and evaluate a rapid and effective method to detect Vibrio parahaemolyticus, a leading pathogen causing seafood-borne gastroenteritis. A newly designed loop-mediated isothermal amplification (LAMP) assay including a short enrichment period was optimized. This assay correctly detected all the target strains $(n=61)$ but none of the non-target strains $(n=34)$. Very low numbers of $V \cdot$ parahaemolyticus ( 2 colony forming unit (CFU) per gram of seafood) could be detected within $3 \mathrm{~h}$ and the minimum time of the whole assay was only $5 \mathrm{~h}$. Comparative screening of various seafood samples $(n=70)$ indicated that the LAMP assay is superior to polymerase chain reaction (PCR) and conventional culture methods because it is more rapid and less complex. This highly sensitive LAMP assay can be applicable as the method of choice in large-scale and rapid screening of seafood and environmental samples to detect $V$. parahaemolyticus strains.
\end{abstract}

Key words Vibrio parahaemolyticus; loop-mediated isothermal amplification; rapid detection; enrichment culture; seafood

Vibrio parahaemolyticus is one of the most important seafood-borne pathogen causing gastrointestinal disorders to humans. This halophilic Gram-negative bacterium was first identified as a causative agent of human gastroenteritis in Japan in 1950. ${ }^{1)}$ However, V. parahaemolyticus can occur ubiquitously in the brackish coastal environment of most continents and infections associated with seafood contaminated by this pathogen have occurred throughout the world. ${ }^{2-4)}$ Particularly, the worldwide spread of the $V$. parahaemolyticus O3:K6 serotype after its emergence in Asia in 1995, it has become very important to identify this pathogenic species in a rapid and sensitive manner. ${ }^{5)}$ At present, the outbreak of $V$. parahaemolyticus infections is a significant public health concern in many countries including China, Japan and U.S.A. ${ }^{6,7)}$

Seafood is very popular in many countries, and simple and specific identification of a pathogen from seafood samples is essential for taking preventive and curative measures. Conventional methods for the diagnosis of $V$. parahaemolyticus include cultivation of bacteria on selective media followed by biochemical tests. However, the traditional phenotypic identification is problematic, it is very time-consuming requiring 3-7d and not highly specific because several Vibrio species display similar biochemical characteristics, which make it difficult for rapid identification of $V$. parahaemolyticus. ${ }^{8)}$ To circumvent this problem, the identification of $V$. parahaemolyticus by rapid and specific molecular techniques targeting the genes encoding thermostable direct haemolysin (TDH) and TDH-related haemolysin (TRH) were developed..$^{9-11)}$ However,

\footnotetext{
†Present address: International Centre for Diaaroheal Diseases Research;
} Bangladesh, Mohakhali, Dhaka 1212, Bangladesh. these genes are only found in pathogenic strains and most $V$. parahaemolyticus isolates from the environment sources do not produce TDH or TRH. ${ }^{3,12)}$ Besides, there are reports of toxigenic factors other than $\mathrm{TDH}$ or $\mathrm{TRH}$, e.g., type III secretion system 2, associated with clinical $V$. parahaemolyticus strains. ${ }^{13)}$ Epidemiological and ecological surveillance on the overall population of a potentially pathogenic species is required as horizontal transfer of toxigenic genes can equip the non-toxigenic strains with epidemic potential. ${ }^{14)}$ The $t$ lh/ldh gene was present in all $V$. parahaemolyticus isolates from both clinical and environmental sources but was absent in other Vibrio species. The $t l h / l d h$ gene appears to be specific to $V$. parahaemolyticus by polymerase chain reaction (PCR) assay. Therefore, it may be appropriate to target $t$ lh/ldh gene for the detection of $V$. parahaemolyticus. ${ }^{11,15-17)}$ The loop-mediated isothermal amplification (LAMP) method described by Notomi et al. is more advantageous than the PCR assay because it is more rapid, easier to perform and does not necessarily require expensive thermal cycler machine. ${ }^{18)}$ In the LAMP method it is possible to amplify DNA fragments within $90 \mathrm{~min}$ by using only water bath or heat block. Previous studies have reported the sensitivity of the LAMP method ranges from $10^{2}$ to $10^{5}$ colony forming unit (CFU)/g V. parahaemolyticus in spiked oysters. ${ }^{17,19)}$ However, seafood with low levels of V. parahaemolyticus has potential risks to human infection because a small number of this pathogen, e.g., ca. $10^{2}$ cells $/ g$ seafood, can increase substantially, e.g., $>10^{5}$ cells/g seafood, within 2 to $3 \mathrm{~h}$ at temperatures between $20^{\circ} \mathrm{C}$ and $35^{\circ} \mathrm{C} .^{20)}$ Therefore, it is necessary to develop a more sensitive method for the detection of $V$. parahaemolyticus strains in seafood.

The objectives of this study were to develop a new LAMP 
assay targeting the $t$ lh/ldh gene in combination with a short period of enrichment for rapid and sensitive detection of $V$. parahaemolyticus in seafood samples and to evaluate this assay with the PCR and conventional culture methods. This simple and sensitive assay would be helpful for epidemiologists, physicians and ecologists in early diagnosis of $V$. parahaemolyticus contaminations in seafood or other samples.

\section{MATERIALS AND METHODS}

Bacterial Strains and DNA Templates Preparation A total of $61 \mathrm{~V}$. parahaemolyticus strains including one reference strain (ATCC 17802) and 21 strains representing nine important pathogenic Vibrio species were used in this study to evaluate the specificity of the LAMP assay. Besides, 13 strains of other important bacterial species were also included, e.g., Listeria spp., Escherichia coli, Cronobacter sakazakii, Lactobacillus spp., Salmonella Typhimurium, Staphylococcus aureus and Streptococcus thermophilus. Details of these strains are described in Table 1. The bacterial strains were maintained in brain heart infusion broth (BHI; Becton, Dickinson NJ, U.S.A.). All the $V$. parahaemolyticus strains were kindly donated by Hebei Province Center for Disease Control and Prevention, China. Other bacterial strains were obtained from the culture collection of the College of Light Industry and Food Sciences, South China University of Technology. All Vibrio strains were cultured using BHI agar or broth supplemented with $3 \% \mathrm{NaCl}$ at $35^{\circ} \mathrm{C}$ overnight. Non-Vibrio strains were also grown on BHI agar. To prepare DNA template, a single freshly grown bacterial colony was suspended in $100 \mu \mathrm{L}$ of TE buffer (10 mm Tris- $\mathrm{HCl}, \mathrm{pH} 8.0 ; 1 \mathrm{~mm}$ ethylenediaminetetraacetic acid (EDTA); Sigma-Aldrich, China). Then the suspension was heated at $100^{\circ} \mathrm{C}$ for $10 \mathrm{~min}$ followed by quick cooling on ice for $5 \mathrm{~min}$. The cell lysate was centrifuged at $12000 \times \mathbf{g}$ for $2 \mathrm{~min}$ and the supernatant containing the extracted DNA was stored at $-20^{\circ} \mathrm{C}$ until use.

Detection of $\boldsymbol{V}$. parahaemolyticus Cells in Spiked Oysters The spiked oysters were prepared as described previously with slight modifications. ${ }^{19)}$ Oysters were obtained from local retail market and confirmed as $V$. parahaemolyticus-negative following methods as described previously. ${ }^{21)} \mathrm{A}$ portion of the oyster sample $(25 \mathrm{~g})$ was mixed with $225 \mathrm{~mL}$ of $3 \% \mathrm{NaCl}$ alkaline peptone water (APW, pH 8.5; Becton, Dickinson) and homogenized in a BagMixer $^{\circledR}(400 \mathrm{v} / \mathrm{w}$; Interscience, Saint Nom, France) for 1 to $2 \mathrm{~min}$. $V$. parahaemolyticus ATCC 17802 strain was grown in APW media at $35^{\circ} \mathrm{C}$ for $6-8 \mathrm{~h}$ until the mid-log phase and then the culture was serially diluted 10-fold in phosphate-buffered saline. Each dilution was spread on $\mathrm{BHI}$ agar supplemented with $3 \% \mathrm{NaCl}$ to determine bacterial counts after overnight incubation at $35^{\circ} \mathrm{C}$. One milliliter of each dilution was inoculated into $9 \mathrm{~mL}$ of the oyster homogenate. Thereafter, $1 \mathrm{~mL}$ of each of the mixture was put into a $1.5 \mathrm{~mL}$-fresh tube and centrifuged at $12000 \times \boldsymbol{g}$ for $5 \mathrm{~min}$ and the harvested cell pellets were suspended into $100 \mu \mathrm{L}$ of TE. To obtain the DNA preparation, the cell suspension was boiled, and an aliquot $(2 \mu \mathrm{L})$ of the preparation was used for both LAMP and PCR amplifications.

Optimization of Enrichment Culture Time Inocula representing $50 \mathrm{CFU}$ of $V$. parahaemolyticus were mixed with $25 \mathrm{~g}$ of each of the oyster samples obtained from local seafood retail market so that the ultimate dose of the inoculated
$V$. parahaemolyticus become $2 \mathrm{CFU} / \mathrm{g}$ oyster. The inoculated oyster samples were aseptically placed in a disposable plastic bag containing $225 \mathrm{~mL}$ of APW ( $\mathrm{pH} 8.5$ ) supplemented with $3 \% \mathrm{NaCl}$ and homogenized as previously described. ${ }^{21)}$ After enrichment for 2-, 3-, 4-, 5-, 6-, 7- or 8-h at $35^{\circ} \mathrm{C}$ (180 rounds/ min) $1 \mathrm{~mL}$ portion of the homogenized samples was put into a $1.5 \mathrm{~mL}$-fresh tube and centrifuged at $3000 \times \boldsymbol{g}$ for $5 \mathrm{~min}$. Thereafter, the supernatant was collected and centrifuged again at $12000 \times \boldsymbol{g}$ for $5 \mathrm{~min}$ to pellet the bacterial cells. The harvested cells were suspended into $100 \mu \mathrm{L}$ of TE and boiled DNA template was prepared as mentioned earlier. ${ }^{21)}$ An aliquot $(2 \mu \mathrm{L})$ of the preparation was used for LAMP amplification. The LAMP assays were repeated three times, according to the time of yielding the amplification curve in a real-time turbidimeter (LA-320C; Eiken Chemical, Co., Ltd., Toyko, Japan), and the shortest cultivation time for detection of $V$. parahaemolyticus was determined.

Detection of $\boldsymbol{V}$. parahaemolyticus in Seafood Samples Seventy seafood samples were randomly acquired from local retail markets and analyzed within the products' shelf life. These samples included 10 of each of the seven categories of seafood representing sleeve-fish, cuttlefish, jellyfish, tegillarca, oyster, weever and shrimp. Each of the seafood samples $(25 \mathrm{~g})$ was aseptically placed in a disposable plastic bag containing $225 \mathrm{~mL}$ of APW ( $\mathrm{pH} 8.5$ ) supplemented with $3 \% \mathrm{NaCl}$, and homogenized and cultured at $35^{\circ} \mathrm{C}$ until the optimized time period as described earlier. $V$. parahaemolyticus was detected and identified by the conventional culture as well as the LAMP methods. The conventional phenotypic culture based identification was performed according to a previously described method. ${ }^{8)}$ Briefly, one loopful of the enriched culture was spread onto a thiosulfate citrate bile salt sucrose (TCBS) agar plate (Eiken Chemical, Co., Ltd.) using a disposable loop and incubated at $37^{\circ} \mathrm{C}$ for $24 \mathrm{~h}$, and green either yellowish, round and large colonies on a plate were subjected to selective biochemical tests.

The Real-Time Turbidimeter LAMP Assay and PCR for Detection of $\boldsymbol{V}$. parahaemolyticus A set of the outer primers (F3: 5'-GCGCAA GGT TACAAC ATC AC-3' and B3: 5'-ATG CGTGACATCCCAGAAC-3') and the inner primers (FIP: 5'GCG TTC ACG AAA CCG TGC TCT TTT TTT ATT CGT CAC GCC TTG TTCG-3' and BIP: 5'-TTGGACATCAACCGC TCA TCG TTT TTG ACGCTGCAC ACT CAGAG-3') were designed from the nucleotide sequence of $t h / l d h$ by PrimerExplorer V4 software (Eiken Chemical; http://primerexplorer.jp/elamp4.0.0/ index.html). The LAMP reactions were carried out using a Loopamp DNA amplification kit (Eiken Chemical Co., Ltd.). The $25 \mu \mathrm{L}$ volume reaction mixture contained $40 \mathrm{pmol}$ each of FIP and BIP, 5 pmol each of F3 and B3 primers, $2 \mu \mathrm{L}$ of template, $1 \mu \mathrm{L}(8 \mathrm{U})$ of $B s t$ DNA polymerase and $12.5 \mu \mathrm{L}$ of reaction mix prepared in the kit. The LAMP assay was accomplished by incubating the reaction mixture at $63^{\circ} \mathrm{C}$ for $60 \mathrm{~min}$ in a Loopamp real-time turbidimeter LA-320C (Eiken Chemical, Co., Ltd.).

All the strains belonging to target as well as non-target species (Table 1) were verified by both the LAMP assay and a PCR method using the LAMP outer primers (F3 and B3). Occurrence of $V$. parahaemolyticus in food samples was also detected by both the LAMP assay and PCR method. Preparation of the reaction mixture and thermal conditions for the PCR was followed according to a previously described method. ${ }^{22}$ ) 
Table 1. Bacterial Strains Used in This Study

\begin{tabular}{|c|c|c|c|c|}
\hline \multirow{2}{*}{ Species $(n)$} & \multirow{2}{*}{ Strains } & \multirow{2}{*}{ Source $^{a)}$} & \multicolumn{2}{|c|}{ Molecular detection } \\
\hline & & & PCR & LAMP \\
\hline \multirow[t]{2}{*}{ Vibrio parahaemolyticus (61) } & $17802^{\mathrm{T}}$ & ATCC & $61 / 61$ & $61 / 61$ \\
\hline & $\mathrm{Vp} 1$ to $\mathrm{Vp} 60$ & HPCDCP & & \\
\hline \multirow[t]{4}{*}{ Vibrio vulnificus (10) } & $27562^{\mathrm{T}}$ & ATCC & $0 / 10$ & $0 / 10$ \\
\hline & $01745^{\mathrm{T}}$ & $\mathrm{ACCC}$ & & \\
\hline & $10383,10384,21615$ & CICC & & \\
\hline & $\begin{array}{l}\text { 1H00066, 1D00023, 1B00281, } \\
1 \mathrm{H} 00047,1 \mathrm{~A} 02606\end{array}$ & $\mathrm{MCCC}$ & & \\
\hline \multirow[t]{2}{*}{ Vibrio harveyi (2) } & $14126^{\mathrm{T}}$ & ATCC & $0 / 2$ & $0 / 2$ \\
\hline & 1.1601 & CGMCC & & \\
\hline \multirow[t]{2}{*}{ Vibrio alginolyticus (2) } & $17749^{\mathrm{T}}$ & ATCC & $0 / 2$ & $0 / 2$ \\
\hline & 1.1607 & CGMCC & & \\
\hline Vibrio fluvialis (2) & $1.1612,1.1609$ & CGMCC & $0 / 2$ & $0 / 2$ \\
\hline Vibrio cholerae (1) & $14035^{\mathrm{T}}$ & ATCC & $0 / 1$ & $0 / 1$ \\
\hline Vibrio mimicus $(1)$ & 21613 & $\mathrm{CICC}$ & $0 / 1$ & $0 / 1$ \\
\hline Vibrio natriegens (1) & 1.1619 & CGMCC & $0 / 1$ & $0 / 1$ \\
\hline Vibrio splendidus (1) & 1D00149 & MCCC & $0 / 1$ & $0 / 1$ \\
\hline Vibrio cincinnatiensis (1) & $1 \mathrm{H} 00030$ & MCCC & $0 / 1$ & $0 / 1$ \\
\hline Listeria monocytogenes (1) & $19115^{\mathrm{T}}$ & ATCC & $0 / 1$ & $0 / 1$ \\
\hline Listeria innocua (1) & $11288^{\mathrm{T}}$ & NCTC & $0 / 1$ & $0 / 1$ \\
\hline Listeria ivanovii (1) & $11846^{\mathrm{T}}$ & NCTC & $0 / 1$ & $0 / 1$ \\
\hline Listeria seeligeri (1) & $11856^{\mathrm{T}}$ & NCTC & $0 / 1$ & $0 / 1$ \\
\hline Listeria welshimeri (1) & $11857^{\mathrm{T}}$ & NCTC & $0 / 1$ & $0 / 1$ \\
\hline Escherichia coli $(1)$ & $10418^{\mathrm{T}}$ & NCTC & $0 / 1$ & $0 / 1$ \\
\hline Cronobacter sakazakii (1) & $29544^{\mathrm{T}}$ & ATCC & $0 / 1$ & $0 / 1$ \\
\hline Lactobacillus casei (1) & $393^{\mathrm{T}}$ & ATCC & $0 / 1$ & $0 / 1$ \\
\hline Lactobacillus delbrueckii (1) & $12315^{\mathrm{T}}$ & ATCC & $0 / 1$ & $0 / 1$ \\
\hline Salmonella Typhimurium (1) & $13311^{\mathrm{T}}$ & ATCC & $0 / 1$ & $0 / 1$ \\
\hline Staphylococcus aureus (1) & $29213^{\mathrm{T}}$ & ATCC & $0 / 1$ & $0 / 1$ \\
\hline Streptococcus thermophilus (1) & $19258^{\mathrm{T}}$ & ATCC & $0 / 1$ & $0 / 1$ \\
\hline
\end{tabular}

a) ATCC, American Type Culture Collection; ACCC, Agricultural Culture Collection of China; CGMCC, China General Microbiological Culture Collection Center; CICC, China Center of Industrial Culture Collection; MCCC, Marine Culture Collection of China; NCTC, National Collection of Type Cultures, U.K.

The PCR products (amplicon size 210bp) were subjected to $2.0 \%$ agarose gel electrophoresis in TAE $(40 \mathrm{mmol} / \mathrm{L}$ Trisacetate, $1 \mathrm{mmol} / \mathrm{L}$ EDTA) buffer followed by staining in ethidium bromide solution $(2 \mu \mathrm{g} / \mathrm{mL})$ and destaining in distilled water for $5-10 \mathrm{~min}$ each. Afterwards images were captured by Gel-Doc 2000 (Bio-Rad, CA, U.S.A.).

\section{RESULTS AND DISCUSSION}

Specificity and Sensitivity of LAMP Detection In the recent decade, increase in seafood-borne infections caused by $V$. parahaemolyticus, is a major concern and a simple and effective method for rapid detection of this bacterium is required. ${ }^{5,23)}$ In this study, the LAMP assay using a real-time turbidimeter could successfully detect $V$. parahaemolyticus ATCC 17802, as well as all other target $V$. parahaemolyticus strains $(n=60)$, while it showed negative results for 33 other non-target bacterial strains (Table 1, data not shown). Therefore, the sensitivity and specificity of this assay was $100 \%$. This indicates that the genetic regions selected for the primers of the LAMP assay are highly conserved among the $V$. parahaemolyticus strains and the newly developed LAMP assay of this study was highly specific. Similarly, no false positive or negative results were observed by PCR using F3/B3 primers (Table 1). A high efficiency of the PCR-based detection of $V$. parahaemolyticus strains targeting the th/ldh gene has been reported by other studies. ${ }^{11,24)}$ Other possible target genes for the specific detection of $V$. parahaemolyticus by LAMP assay include the $g y r B$, encoding the B subunit of DNA gyrase, and virulence regulatory tox $R$ genes, both of which have been successfully used in PCR assays. ${ }^{25,26)}$

The detection limit of V. parahaemolyticus ATCC 17802 cells in the spiked oyster samples by the LAMP assay is revealed in Fig. 1. In case of spiked oyster samples without enrichment, the real time turbidimeter could easily detect amplification signals generated from higher concentration of target cells $\left(4.0 \times 10^{7} \mathrm{CFU} / \mathrm{mL}\right.$ homogenates $)$ at $c a .30 \mathrm{~min}$. The detection of positive signals by the turbidimeter was delayed with decreasing number of cells and the LAMP assay detected as low as $4.0 \times 10^{4} \mathrm{CFU} / \mathrm{mL}$ concentration of $V$. paraheamolyticus in the homogenate samples after ca. $40 \mathrm{~min}$. However, in case of pure culture of $V$. parahaemolyticus, the sensitivity of the LAMP assay was 10 -fold higher (i.e., $4.0 \times 10^{3} \mathrm{CFU} / \mathrm{mL}$ ) than that for the spiked oyster sample (data not shown). This indicates that food component, such as blood, calcium ion and other substances, might interfere with the LAMP reaction. Thus, the application of a more sensitive detection method is required to detect the low concentration $\left(<10^{3} \mathrm{CFU} / \mathrm{g}\right)$ of $V$. parahaemolyticus populations. The LAMP assay developed in this study can be considered as very efficient as the highly 
efficient PCR or LAMP assays have a detection limit of $10^{3}$ to $10^{4}$ cells $/ \mathrm{mL}$ of sample, i.e., $c a$. 1 to 10 cells $/ \mu \mathrm{L}$ or 1 to 10 cells per reaction tube. ${ }^{17,26)}$

Optimization of Enrichment Culture Time The present study attempted to detect a very few number of $V$. parahae-

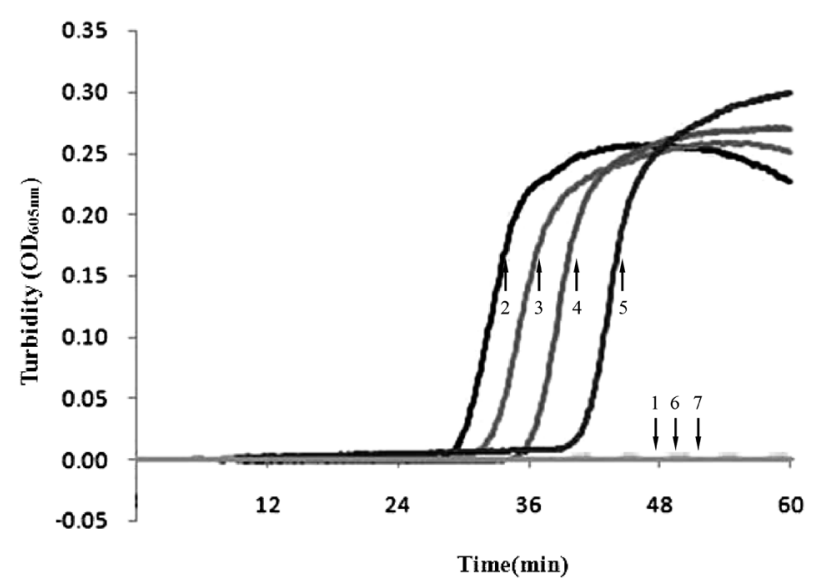

Fig. 1. Sensitivity of LAMP Assay to Detect $V$. parahaemolyticus ATCC 17802 in Spiked Oyster Samples without Enrichment

Sample 1, water used as a negative control; and samples $2-7$, ten-fold serial dilutions of $V$. parahaemolyticus $\left(4.0 \times 10^{7}\right.$ to $\left.4.0 \times 10^{2} \mathrm{CFU} / \mathrm{mL}\right)$. Higher concentration of target cells $\left(4.0 \times 10^{7} \mathrm{CFU} / \mathrm{mL}\right)$ produced positive signal at $c a .30 \mathrm{~min}$. However, this assay detected up to $4.0 \times 10^{4} \mathrm{CFU} / \mathrm{mL}$ concentration of $V$. parahaemolyticus which produced positive signal at $c a .40 \mathrm{~min}$.

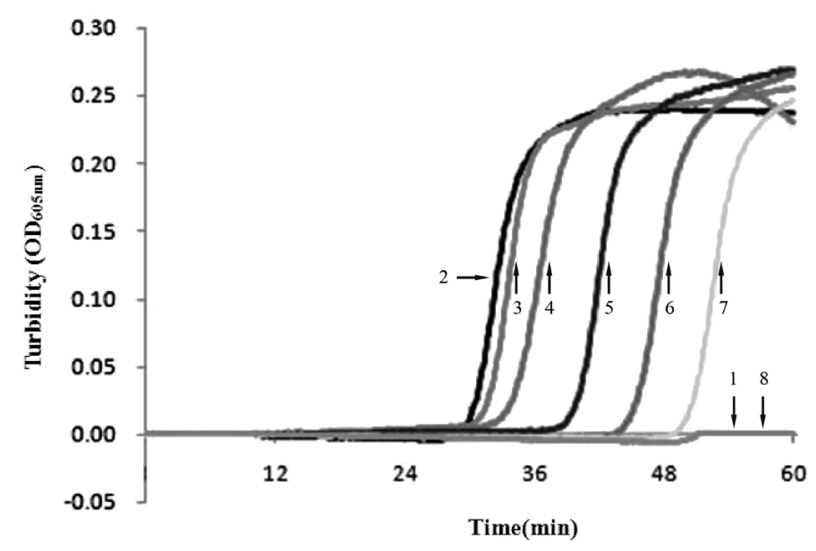

Fig. 2. Optimization of Enrichment Culture Period of LAMP Assay

V. parahaemolyticus ATCC 17802 was inoculated into oysters free of this pathogenic species at a very low concentration $(2 \mathrm{CFU} / \mathrm{g})$, and the oysters were homogenized and subjected to the enrichment culture. Thereafter, the culture was withdrawn periodically, and the LAMP assay to detect $V$. parahaemolyticus was performed. Sample 1, water used as a negative control; and samples 2-8 represent periodic enrichment cultures, i.e., 8-, 7-, 6-, 5-, 4-, 3- and 2-h enrichment culture of $V$. parahaemolyticus ATCC 17802, respectively. molyticus (ca. 2CFU/g seafood sample) by employing the LAMP assay after a brief enrichment period. As illustrated in Fig. 2, although no amplification curve was yielded in the real-time turbidimeter after 2-h enrichment, the positive LAMP results were detected when the DNA samples were prepared from 3-, 4-, 5-, 6-, 7- and 8-h enrichments. The signal curves representing the enrichment samples of 7- and 8-h almost superimposed each other indicating reaching of a stationary phase of the inoculated $V$. parahaemolyticus populations. Comparative analysis of the signal curves of LAMP assay representing seafood sample containing $\mathrm{ca} .10^{4} \mathrm{CFU} / \mathrm{mL}$ inoculum of $V$. parahaemolyticus without enrichment (Fig. 1) and a 3-h enrichment of seafood sample inoculated with $c a$. $2 \mathrm{CFU} / \mathrm{g}$ V. parahaemoluticus (Fig. 2) having detection time of ca. 40 and $c a .48 \mathrm{~min}$, respectively, indicates that the number of $V$. parahaemolytics population was $<10^{4} \mathrm{CFU} / \mathrm{mL}$ after $3 \mathrm{~h}$ enrichment. Therefore, the LAMP assay developed in this study is highly efficient to detect even a very low number of $V$. parahaemolyticus cells after $3 \mathrm{~h}$ enrichment in APW (3\% $\mathrm{NaCl}$ ). It is important to detect the presence of few cells of $V$. parahaemolyticus in seafood samples because this bacterium can rapidly grow at room temperature $\left(25^{\circ} \mathrm{C}\right.$, more or less) reaching to the pathogenic dose. ${ }^{20)} \mathrm{A}$ recent study with enrichment-based LAMP assay required $17-19 \mathrm{~h}$ for the final determination. ${ }^{8)}$ On the other hand, the LAMP assay developed in the present study including the enrichment, DNA extraction and LAMP amplification steps can be completed within $5 \mathrm{~h}$, which advocates the usefulness of this assay as a superior method of choice for the large-scale screening of seafood and other environmental samples.

Evaluation of the LAMP Assay in Detection of $\boldsymbol{V}$. parahaemolyticus in Seafood Samples A total of 70 seafood samples were evaluated by the newly developed LAMP assay combined with enrichment to detect the presence of $V$. parahaemolyticus, and the results were compared with those of a conventional culture as well as PCR methods. As shown in Table 2, V. parahaemolyticus was isolated from 11 of 70 seafood samples $(15.7 \%)$ tested by the conventional method, and all of them were also positive by the LAMP assay. However, the PCR method appeared to be less effective as it detected $V$. parahaemolyticus in 10 out of these 11 positive samples and failed to detect the presence of $V$. parahemolyticus in one sample (cuttlefish), which was positive by the LAMP and culture methods. Seafood samples in which $V$. parahaemolyticus was detected were cuttlefish (40\%), sleevefish (30\%), jellyfish (20\%), weever (10\%) and shrimp (10\%). For isolation and identification of $V$. parahaemolyticus from naturally con-

Table 2. Detection of $V$. parahaemolyticus in Retail Seafood Samples

\begin{tabular}{|c|c|c|c|c|c|c|}
\hline \multirow{2}{*}{ Samples } & \multicolumn{2}{|c|}{ Conventional method } & \multicolumn{2}{|c|}{ PCR } & \multicolumn{2}{|c|}{ LAMP } \\
\hline & + & - & + & - & + & - \\
\hline Cuttlefish $(n=10)$ & $4^{a)}$ & 6 & $3^{a)}$ & 7 & 4 & 6 \\
\hline Sleevefish $(n=10)$ & $3^{a)}$ & 7 & $3^{a)}$ & 7 & 3 & 7 \\
\hline Jellyfish $(n=10)$ & $2^{a)}$ & 8 & $2^{a)}$ & 8 & 2 & 8 \\
\hline Weever $(n=10)$ & $1^{a)}$ & 9 & $1^{a)}$ & 9 & 1 & 9 \\
\hline Shrimp $(n=10)$ & $1^{a)}$ & 9 & $1^{a)}$ & 9 & 1 & 9 \\
\hline Tegillarca $(n=10)$ & 0 & 10 & 0 & 10 & 0 & 10 \\
\hline Oyster $(n=10)$ & 0 & 10 & 0 & 10 & 0 & 10 \\
\hline
\end{tabular}

a) LAMP positive. 
taminated seafood by conventional culture method, it requires more than two days in comparison to only $5 \mathrm{~h}$ by the LAMP assay developed in this study. Besides, in case of detection by conventional culture the growth of $V$. parahaemolyticus strains on selective media can be occasionally inhibited due to overgrowth of other naturally occurring vibrios in seafood samples, such as $V$. alginolyticus. ${ }^{8)}$

Utilization of the enrichment-PCR method $^{27,28)}$ also requires more time than the newly developed assay of this study, as additional gel-run and detection procedures are required after PCR step which is avoided by the use of real-time turbidimeter in the LAMP assay. A recent study has reported successful utilization of real-time PCR method after a $6 \mathrm{~h}$ enrichment period in detecting less than $5 \mathrm{~V}$. parahaemolyticus cells/g of seafood ${ }^{29)}$ however, this method is more expensive and complex, and requires more time than the LAMP assay of the present study. In addition to rapid detection, the LAMP assay has other advantages, such as quantitative measurement, a lower contamination rate, higher sensitivity and specificity, and easy standardization. ${ }^{19)}$ The high sensitivity and rapidity of our LAMP assay make it an effective tool for risk assessment of $V$. parahaemolyticus in seafood, which is an increasingly important issue worldwide.

In conclusions, in this study, a LAMP assay has been developed and optimized using a short enrichment step to detect $V$. parahaemolyticus strains in seafood samples. The newly designed primers targeting the $t h / t d h$ gene were species-specific and highly sensitive. As few as $2 \mathrm{CFU} / \mathrm{g} V$. parahaemoluticus can be detected by the LAMP assay and this technique can be highly efficient in precise detection of this pathogenic species. Comparative evaluation with various seafood samples revealed that this newly developed LAMP assay combined with a short enrichment period is superior to the conventional culture as well as PCR methods. Therefore, the LAMP assay of the present study can be very useful in large-scale screening of seafood and environmental samples in a sensitive and rapid manner. This method would greatly aid the identification of $V$. parahaemolyticus strains from other Vibrio or pathogenic species involved in disease outbreaks during catastrophe when time is critical.

Acknowledgments This work was supported by the Major State Basic Research Development Program of China (973 Program) (No. 2010CB35704; No. 2012CB723705), Guangzhou technological planning projects (11C12080718), Xiamen Science and Technology Major Project (3502Z20110001), Guangdong Province Nature Science Foundation, China (10451064101005159), and the Food Safety Key Lab of Liaoning Province Open Project Funding (LNSAKF2011002).

Conflict of Interest The authors declare no conflict of interest.

\section{REFERENCES}

1) Fujino $T$, Okuno Y, Nakada D, Aoyama A, Fukai K, Mukai T, Ueho T. On the bacteriological examination of shirazu-food poisoning. Med. J. Osaka Univ., 4, 299-304 (1953).

2) Nair GB, Sarkar BL, Abraham M, Pal SC. Serotypes of Vibrio parahaemolyticus isolates from hydrobiologically dissimilar aquatic environments. Appl. Environ. Microbiol., 50, 724-726 (1985).
3) DePaola A, Nordstrom JL, Bowers JC, Wells JG, Cook DW. Seasonal abundance of total and pathogenic Vibrio parahaemolyticus in Alabama oysters. Appl. Environ. Microbiol., 69, 1521-1526 (2003).

4) Mahmud ZH, Neogi SB, Kassu A, Wada T, Islam MS, Nair GB, Ota F. Seaweeds as a reservoir for diverse Vibrio parahaemolyticus populations in Japan. Int. J. Food Microbiol., 118, 92-96 (2007).

5) Nair GB, Ramamurthy T, Bhattacharya SK, Dutta B, Takeda Y, Sack DA. Global dissemination of Vibrio parahaemolyticus serotype 03:K6 and its serovariants. Clin. Microbiol. Rev., 20, 39-48 (2007).

6) Su YC, Liu C. Vibrio parahaemolyticus: A concern of seafood safety. Food Microbiol., 24, 549-558 (2007).

7) Vugia D, Cronquist A, Cartter M, Tobin-D'Angelo M, Blythe D, Smith K, Lathrop S, Morse D, Cieslak P, Dunn J, Centers for Disease Control and Prevention (CDC). Preliminary FoodNet data on the incidence of infection with pathogens transmitted commonly through food-10 states, 2008. MMWR Morb. Mortal. Wkly. Rep., 58, 333-337 (2009).

8) Yamazaki W, Kumeda Y, Uemura R, Misawa N. Evaluation of a loop-mediated isothermal amplification assay for rapid and simple detection of Vibrio parahaemolyticus in naturally contaminated seafood samples. Food Microbiol., 28, 1238-1241 (2011).

9) Honda T, Ni Y, Miwatani T. Purification and characterization of a hemolysin produced by a clinical isolate of Kanagawa phenomenonnegative Vibrio parahaemolyticus and related to the thermostable direct hemolysin. Infect. Immun., 56, 961-965 (1988).

10) Tada J, Ohashi T, Nishimura N, Shirasaki Y, Ozaki H, Fukushima S, Takano J, Nishibuchi M, Takeda Y. Detection of the thermostable direct hemolysin gene $(t d h)$ and the thermostable direct hemolysinrelated hemolysin gene (trh) of Vibrio parahaemolyticus by polymerase chain reaction. Mol. Cell. Probes, 6, 477-487 (1992).

11) Bej AK, Patterson DP, Brasher CW, Vickery MCL, Jones DD, Kaysner CA. Detection of total and hemolysin-producing Vibrio parahaemolyticus in shellfish using multiplex PCR amplification of tdh and trh. J. Microbiol. Methods, 36, 215-225 (1999).

12) Cook DW, Oleary P, Hunsucker JC, Sloan EM, Bowers JC, Blodgett RJ, Depaola A. Vibrio vulnificus and Vibrio parahaemolyticus in U.S. retail shell oysters: a national survey from June 1998 to July 1999. J. Food Prot., 65, 79-87 (2002).

13) Park KS, Ono T, Rokuda M, Jang MH, Okada K, Iida T, Honda T. Functional characterization of two type III secretion systems of Vibrio parahaemolyticus. Infect. Immun., 72, 6659-6665 (2004).

14) Waldor MK, Mekalanos JJ. Lysogenic conversion by a filamentous phage encoding cholera toxin. Science, 272, 1910-1914 (1996).

15) Shinoda S, Matsuoka H, Tsuchie T, Miyoshi S, Yamamoto S, Taniguchi H, Mizuguchi Y. Purification and characterization of a lecithin-dependent haemolysin from Escherichia coli transformed by a Vibrio parahaemolyticus gene. J. Gen. Microbiol., 137, 2705-2711 (1991).

16) Nordstrom JL, Vickery MCL, Blackstone GM, Murray SL, DePaola A. Development of a multiplex real-time PCR assay with an internal amplification control for the detection of total and pathogenic Vibrio parahaemolyticus bacteria in oysters. Appl. Environ. Microbiol., 73, 5840-5847 (2007).

17) Yamazaki W, Ishibashi M, Kawahara R, Inoue K. Development of a loop-mediated isothermal amplification assay for sensitive and rapid detection of Vibrio parahaemolyticus. BMC Microbiol., 8, 163 (2008).

18) Notomi $\mathrm{T}$, Okayama H, Masubuchi H, Yonekawa T, Watanabe K, Amino N, Hase T. Loop-mediated isothermal amplification of DNA. Nucleic Acids Res., 28, e63 (2000).

19) Chen S, Ge B. Development of a toxR-based loop-mediated isothermal amplification assay for detecting Vibrio parahaemolyticus. BMC Microbiol., 10, 41 (2010).

20) Food and Agriculture Organization of the United Nations. "Risk assessment of Vibrio parahaemolyticus in seafood.”: 〈http://www.who. 
int/foodsafety/publications/micro/MRA_16_JEMRA.pdf), cited 15 October, 2011.

21) Han F, Walker RD, Janes ME, Prinyawiwatkul W, Ge B. Antimicrobial susceptibilities of Vibrio parahaemolyticus and Vibrio vulnificus isolates from Louisiana Gulf and retail raw oysters. Appl. Environ. Microbiol., 73, 7096-7098 (2007).

22) Zhang Y, Shan X, Shi L, Lu X, Tang S, Wang Y, Li Y, Alam M, Yan H. Development of a fimY based loop-mediated isothermal amplification assay for detection of Salmonella in food. Food Res. Int., 45, 1011-1015 (2012).

23) Vugia D, Cronquist A, Cartter M, Tobin-D'Angelo M, Blythe D, Smith K, Lathrop S, Morse D, Cieslak P, Dunn J, Centers for Disease Control and Prevention (CDC). Preliminary foodnet data on the incidence of infection with pathogens transmitted commonly through food 10 states 2008. MMWR Morb. Mortal. Wkly. Rep., 58, 333-337 (2009).

24) Haldar S, Neogi SB, Kogure K, Chatterjee S, Chowdhury N, Hinenoya A, Asakura M, Yamasaki S. Development of a haemolysin gene-based multiplex PCR for simultaneous detection of Vibrio campbellii, Vibrio harveyi and Vibrio parahaemolyticus. Lett. Appl.
Microbiol., 50, 146-152 (2010).

25) Venkateswaran K, Dohmoto N, Harayama S. Cloning and nucleotide sequence of the gyrB gene of Vibrio parahaemolyticus and its application in detection of this pathogen in shrimp. Appl. Environ. Microbiol., 64, 681-687 (1998).

26) Neogi SB, Chowdhury N, Asakura M, Hinenoya A, Haldar S, Saidi SM, Kogure K, Lara RJ, Yamasaki S. A highly sensitive and specific multiplex PCR assay for simultaneous detection of Vibrio cholerae, Vibrio parahaemolyticus and Vibrio vulnificus. Lett. Appl. Microbiol., 51, 293-300 (2010).

27) Alam MJ, Miyoshi S, Shinoda S. Studies on pathogenic Vibrio parahaemolyticus during a warm weather season in the Seto Inland Sea, Japan. Environ. Microbiol., 5, 706-710 (2003).

28) Luan X, Chen J, Liu Y, Li Y, Jia J, Liu R, Zhang XH. Rapid quantitative detection of Vibrio parahaemolyticus in seafood by MPNPCR. Curr. Microbiol., 57, 218-221 (2008).

29) Robert-Pillot A, Copin S, Gay M, Malle P, Quilici ML. Total and pathogenic Vibrio parahaemolyticus in shrimp: fast and reliable quantification by real-time PCR. Int. J. Food Microbiol., 143, 190197 (2010). 